\begin{abstract}
Iranica
Abstracta Iranica Revue bibliographique pour le domaine irano-aryen

Volume 40-41 | 2019

Comptes rendus des publications de 2017-2018
\end{abstract}

\title{
Andrea Squitieri. Stone Vessels in the Near East during the Iron Age and the Persian Period (c. 1200-330 BCE)
}

\section{Astrid Nunn}

\section{(2) OpenEdition}

\section{Édition électronique}

URL : http://journals.openedition.org/abstractairanica/48217

DOI : 10.4000/abstractairanica.48217

ISBN : 1961-960X

ISSN : 1961-960X

Éditeur :

CNRS (UMR 7528 Mondes iraniens et indiens), Éditions de l'IFRI

Référence électronique

Astrid Nunn, «Andrea Squitieri. Stone Vessels in the Near East during the Iron Age and the Persian Period (c. 1200-330 BCE) », Abstracta Iranica [En ligne], Volume 40-41 | 2019, document 15, mis en ligne le 09 août 2019, consulté le 17 avril 2021. URL : http://journals.openedition.org/abstractairanica/48217 ; DOI : https://doi.org/10.4000/abstractairanica.48217

Ce document a été généré automatiquement le 17 avril 2021

Tous droits réservés 


\section{Andrea Squitieri. Stone Vessels in the Near East during the Iron Age and the Persian Period (c. 1200-330 BCE)}

Astrid Nunn 


\section{RÉFÉRENCE}

Andrea Squitieri. Stone Vessels in the Near East during the Iron Age and the Persian Period (c. 1200-330 BCE). Oxford: Archaeopress, 2017. iv+284 pages; 50 plates in colour,

(Archaeopress Ancient Near Eastern Archaeology 2)

1 En général seules les vaisselles néolithiques en pierre attirent l'attention des scientifiques. L'A. a porté son choix sur les vaisselles tardives, liées à une époque de grands changements, sinon même de ruptures. Selon l'A. les vaisselles de ce type, dont il essaie de reconstituer la chaîne opératoire, peuvent être un indice de changements économiques et sociaux et de réseaux marchands. L'aire géographique examinée englobe le Proche Orient, avec toutefois un accent sur Israël/Palestine. Les formes sont multiples : bol, mortier, bassin, plat, palette, jarre, alabastron, amphorisque et cruche. Selon la forme finale et selon que la vaisselle soit un outil de travail ou un objet de luxe, la pierre est du basalte, de la diorite, du granite ou des roches calcaires. Peu de formes nouvelles apparaissent à l'époque achéménide, d'autres même disparaissent, tels les vases zoomorphes ou les vases à petits pieds. Inversement apparait pour la première fois dans le Gordion du IVème s. la technique nouvelle du tour pour les alabastres en gypse ou en calcite. L'A. constate un nombre plus élevé de formes et une plus large distribution à partir de l'époque néo-assyrienne, ce qui est visiblement lié à "l'ouverture" des marchés. Les produits levantins se vendent partout et l'influence égyptienne est renforcée. Il s'établit “an international langage of expression” (p. 186). Les alabastres se retrouvent dans toutes les tombes riches de l'Empire achéménide.

\section{AUTEURS}

\section{ASTRID NUNN}

Université de Munich 